aggregating agents. One had a latent von Willebrand disease. The mechanism of the diet-induced bruising may be complex, involving interaction between the diet and individual platelet dysfunction. A possible bleeding tendency should be evaluated in patients on the ketogenic diet who are candidates for surgery or anticoagulant therapy. (Berry-Kravis E, Booth G, Taylor A, Valentino LA. Bruising and the ketogenic diet: evidence for diet-induced changes in platelet function. Ann Neurol January 2001;49:98-103). (Respond: Dr Berry-Kravis, RUSH-Presbyterian-St Luke's Medical Center, 1725 West Harrison Street, Suite 718, Chicago, IL 60612).

COMMENT. Despite the absence of serious bleeding in this series of patients treated with the ketogenic diet, a 30\% incidence of diet-induced bruising deserves further study and evaluation. A possible interaction with lamotrigine is suggested in some patients receiving concurrent drug and diet.

This is not the first observation of platelet dysfunction and anemia as a complication of the ketogenic diet. Complications in $10 \%$ of 52 children treated by Ballaban-Gil et al, 1998 (see Ped Neur Briefs August 1998;12:60) included thrombocytopenia and hemolytic anemia. Valproate interaction could not be excluded in 29 (56\%). The proportion of ketogenic/antiketogenic foods was $4: 1$ in this study but was not specified in the above Pres St Luke's study. This report of diet-induced bruising is another reason to endorse the Mayo Clinic method of slow initiation of the diet with lower ratios, in place of the Hopkins recommended ratio of $4: 1$. Using the Mayo Clinic method, I have not encountered this or other serious complication as reported with the Hopkins regimen (Ped Neur Briefs 1998;12:61).

A fat-overload syndrome with neurologic complications is reported in 2 children receiving fat emulsion therapy. Both patients died and autopsy showed cerebral intravascular lipid deposition and areas of necrosis and hemorrhage. (Schulz PE et al, 1994; Progress in Pediatric Neurology III, PNB Publ, 1997;p98). A rapid rise in triglyceride levels was invoked as a factor in this complication.

\title{
FAMILIAL MESIAL TEMPORAL LOBE EPILEPSY
}

Clinical, genetic, and MR characteristics of 68 patients with familial mesial temporal lobe epilepsy (MTLE) were analysed at the University of CampinasUNICAMP, Brazil. Hippocampal atrophy (HA) was identified by MRI in $48(57 \%)$ of 84 patients examined. HA was present in $46 \%$ of 13 patients with seizure remission, in $51 \%$ of 16 patients whose seizures were well controlled by AEDs, and in all 16 patients with refractory MTLE. HA was also found in some patients without MTLE: in $30 \%$ of 10 patients with febrile seizures alone, $60 \%$ of 10 with generalized tonicclonic epilepsy, and in 1 of 4 with a single partial seizure. Familial MTLE is a heterogeneous syndrome with a genetic component in etiology. (Kobayashi E, Lopes-Cendes I, Guerreiro CAM et al. Seizure outcome and hippocampal atrophy in familial mesial temporal lobe epilepsy. Neurology January (2 of 2) 2001;56:166172). (Reprints: Dr F Cendes, Departamento de Neurologia, Faculdade de Ciencias MedicasUNICAMP, Caixa Postal 6111, Cidade Universitaria Zeferino Vaz Campinas SP, Brazil, CEP 13083-970).

COMMENT. In this series of patients with familial mesial temporal lobe epilepsy, $57 \%$ had MRI evidence of mesial temporal sclerosis. Hippocampal atrophy is found not only in patients with refractory epilepsy but also in patients with a favorable outcome. Genetically determined mechanisms may have a role in hippocampal damage in familial cases of MTLE. In contrast to most patients with temporal lobe epilepsy, a history of febrile seizures is uncommon in patients with familial TLE. 